\title{
DESIGN OF A SIMPLE MUFFLE FURNACE FOR TEMPERATURE OPTIMIZATION IN ASH CONTENT ANALYSIS
}

\author{
Farid R. Abadi* \\ Indonesian Legume and Tuber Crops Research Institute \\ Kendalpayak St. No.66, Kendalpayak, Pakisaji, Malang, Jawa Timur 65162
}

Recieved:12 $2^{\text {th }}$ August 2017; Revised: $23^{\text {th }}$ January 2018; Accepted: $24^{\text {th }}$ April 2018

\begin{abstract}
Ash analysis of biomass conducted through the incineration process in the muffle furnace at a given temperature of $575 \pm 25^{\circ} \mathrm{C}$. The accuracy level of the design depends on the sensitivity of the temperature sensor arranged in the muffle furnace . It was attempted to achieve the optimum temperature and to detect the muffle furnace temperature by installing the thermocouple sensor type $\mathrm{K}$ directly in the porcelain sample cups. It yielded that by the direct incineration process and the gradual process, the setup point reached in 60-90 minutes and 150-180 minutes for attaining the steady, respectively. The temperature distributed uniformly for all treatments at $\pm 6.61{ }^{\circ} \mathrm{C}$. The temperature measurement accuracy was $\pm 1.18 \%$, and the overall temperature gradient was $\pm 28.69{ }^{\circ} \mathrm{C}$. Moreover, there was no difference in the temperature fluctuation among the treatments at the temperature of \pm $20.95{ }^{\circ} \mathrm{C}$. The optimum temperature of the chamber was $588{ }^{\circ} \mathrm{C}$ for analysis the ash content in biomass.
\end{abstract}

Keywords: Thermocouple Sensor; The Incineration Process; Ash Content Analysis; Biomass.

\section{Introduction}

Ash contains mineral and inorganic residue produced in the combustion process or complete oxidation of organic matter in biomass. There are two types of ashing techniques, i.e., dry and wet ashing. Wet ashing is a prepation step for mineral analysis in case that the mineral might be volatilized or lost during dry ashing. It often continued by the dissolution in hot acid and chemical oxidation. Moreover, dry ashing usually uses the combustion of material at a low temperature that reaches $525{ }^{\circ} \mathrm{C}$ which commonly utilized in a different thermal aplication and research. ${ }^{1,2}$ In this process does water stored in the sample evaporate straightforwardly and remain minerals and organic residue. These minerals convert into oxide, sulphat, phosphate, Chloride and silicates. ${ }^{3}$

The standard procedure for ash analysis according to The Scientific Association *Corresponding author.

E-Mail: farid_ra98@yahoo.com
Dedicated to Analytic Excellent (AOAC) International is heating the samples in 12 up to $18 \mathrm{~h}$ (or overnight) under $550^{\circ} \mathrm{C}$ in a muffle furnace. ${ }^{4}$ Suitler, et. al. ${ }^{5}$, furnace temperature setup for biomass ash content analysis is $575 \pm 25^{\circ} \mathrm{C}$ or in a range 500 to $600{ }^{\circ} \mathrm{C}$. The ash content determined as the percentage of residue after dry oxidation at the specific temperature range $\left(500-600^{\circ} \mathrm{C}\right)$. Also, Ashing process should be performed in two stages for plant samples, i.e., the process at a low temperature and then continued at a high temperature.

Nowadays, an electrical muffle furnace heats up by conduction, convection, or radiation process to obtain a uniform temperature and to assure isolation of the heated material from combustion contaminants. In ash content analysis, the preparation sample plate has to withstand in a high temperature in a particular time and also resist to acid and halogen. ${ }^{6}$ 
The incineration process in muffle furnace is indicated by the temperature rise inside the chamber which depends on the accuracy of the written temperature sensor and the thermo-control setup. The real temperature inside the chamber is not precisely equal with the temperature control device due to sensory process. Therefore, to maintain a precise accuracy and reliable result in the analysis process, the furnace must be periodically calibrated. $^{7}$

The output difference between the actual temperature and th written output in the temperature control setup specify the temperature diversity inside the chamber and also figure out the accuracy in an ashing process. Therefore, The temperature diversity points out the maximum temperature deviation. $^{7}$ According to AMS2750 in Jones and Fradette $^{8}$, the six types of furnace divined based on the expected + and uniformity factor are namely: 1) type $1= \pm 3$ ${ }^{\circ} \mathrm{C} ; 2$ ) type $\left.2= \pm 6{ }^{\circ} \mathrm{C} ; 3\right)$ type $\left.3= \pm 8{ }^{\circ} \mathrm{C} ; 4\right)$ type $4= \pm 10{ }^{\circ} \mathrm{C} ; 5$ ) type $5= \pm 14{ }^{\circ} \mathrm{C}$; and 6 ) type $6= \pm 24{ }^{\circ} \mathrm{C}$. variation of temperature on location inside of the furnace chamber in a period after attaining a balanced state. Records of the difference between the maximum and minimum temperature of the successive output for each of the sensors shall be identified.

The specific method of muffle furnace calibration and temperature uniformity survey refers to the furnace chamber temperature characteristic represented by one or some observation points supported by firm metal frames. It is proposed for describing the average temperature characteristic of a given muffle furnace. Unfortunately, Besides impractical and expensive, This method is not appropriate because, in the real crucible, the ash analysis of biomass is performed by placing the preppparation sample cups in different positions. The experiment conducted to obtain the optimum thermo-temperature setup and understand the characteristic of temperature in the chamber in which the porcelain crucible cups arranged as in figure 1.

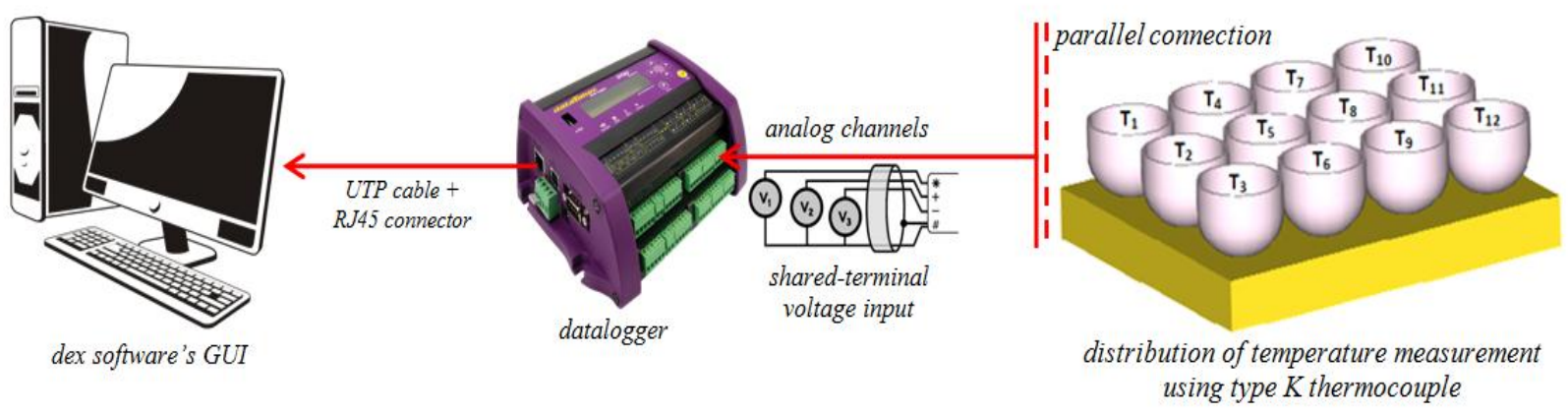

Figure 1. The setup of the experiment.

A muffle furnace performs a similar operation with an oven as thermal devices in analysis. The evaluation of temperature uniformity inside the muffle furnace can be done by surveying the temperature within the work space during the whole treatments. ${ }^{9}$ Moreover, In characterization procedure on the muffel chamber, the temperature gradient is interesting to investigate. It presents the difference between the highest and lowest average temperature value of the temperature sensors in different positions within the working space after achieving stability. Also, a temperature fluctuation represents the

\section{Methods}

Materials and instruments preparation include: Nabertherm muffle furnace (D-2804 Lilienthal/Bremen); ceramic cups; type $\mathrm{K}$ thermocouples with firm-flexible wire; standardized mercury thermometer; data logger (data taker DT80); a personal computer; unshielded twisted pair (UTP) cable and RJ45 (Registered Jack 45) connector. The temperature measurement showed in figure 1 . In figure 1 , the analog signal resulted from the temperature increment is sent to the datalogger to be 
processed into a digital signal. Afterwards, It can be read by a computer using the dex software graphical user interface (GUI). The muffle furnace was initially empty and at room temperature with usual accessories.

The AOAC standard procedure for ash content analysis was performed by placing 12 porcelain crucible cups in the muffle furnace chamber at certain positions. The crucible locations were arranged in 3 rows and 4 columns as seen in Figure 2. The thermocouples junctions were placed inside the crucibles which were parallelly connected to the datalogger's analog channel by the shared-terminal voltage input. ${ }^{10}$ The flexible wire helped to locate the the thermocouple junction ends within the crucible cups. Before operated, the type $\mathrm{K}$ thermocouples were calibrated using the official calibrated mercury thermometer.

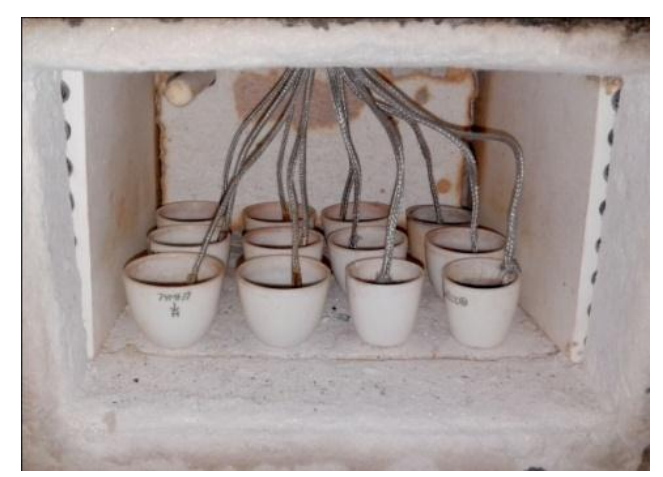

(a)

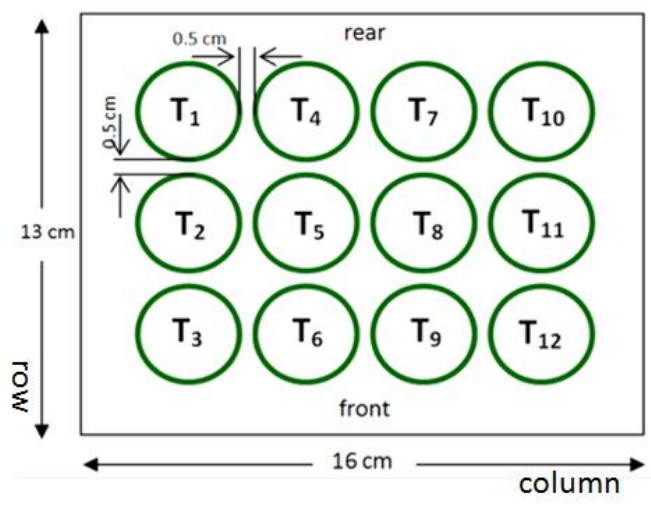

(b)

Gambar 2. The positions of connected thermocouple junctions with the 12 crucibles (a) front view; (b) top view.

The experiment was started by heating up the 12 crucible cup at the temperatures $550^{\circ} \mathrm{C} ; 563^{\circ} \mathrm{C} ; 575^{\circ} \mathrm{C}$ and $588^{\circ} \mathrm{C}$ with the correction $+12.5{ }^{\circ} \mathrm{C}$ based on the deviation recorded in the official calibration. ${ }^{11}$ Two types of incineration were conducted with random temperatures chosen from the final temperature of the direct process $\left(563^{\circ} \mathrm{C}\right.$ and $588^{\circ} \mathrm{C}$ ) and the final temperature of the gradual process $\left(550^{\circ} \mathrm{C}\right.$ and $\left.575^{\circ} \mathrm{C}\right)$ of which the initial temperature was $100^{\circ} \mathrm{C}$ continued to the final temperature after one hour. ${ }^{12}$ The data are recorded and retrieved into computer memory using dex-software which integrated with the datalogger, using a time interval of $i=15 \mathrm{~s}$, followed by data validation and analysis. The analyses include the temperature characteristic, uniformity; temperature gradient; fluctuation; homogeneity and the analysis of variance.

\section{Result and Discussion}

\section{Thermocouple calibration}

The temperature sensors calibrated using a standard mercury thermometer. The used sensors were a type $\mathrm{K}$ of thermocouples with a specific dimension $\varnothing=0.53 \mathrm{~mm}$ in diameter; and $l=172.2 \mathrm{~cm}$ in length. Calibration was conducted in the average room temperature of $\pm 26.5{ }^{\circ} \mathrm{C}$ and the relative humidity of $\pm 60^{\circ} \mathrm{C}$ in standard pressure. The result showed that the calibration equation is $\mathrm{y}=0.960 \mathrm{x}-2.021$; with the determination coefficient of $\mathrm{R}^{2}=0.999$ (Figure 3).

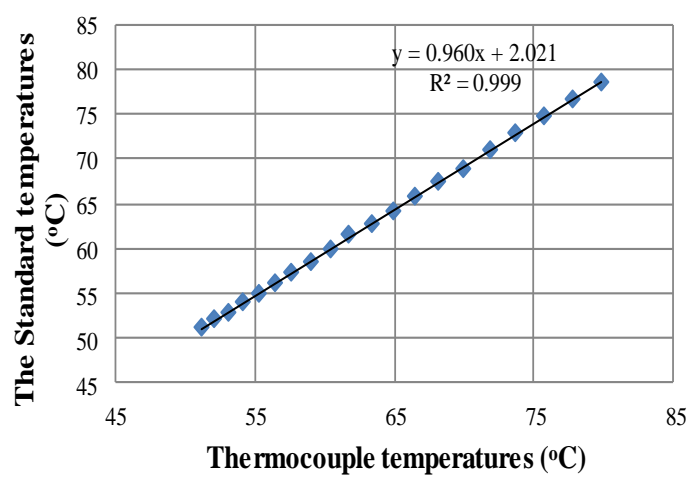

Figure 3. The calibration result of the type $\mathrm{K}$ thermocouple using the standard mercury thermometer. 


\section{The Temperature Performance in $575 \pm$ $25^{\circ} \mathrm{C}$ of Thermo-control Setup}

The all observed data set up at $575 \pm 25^{\circ} \mathrm{C}$ both for the direct and gradual heating. The characteristic temperatures of the chamber show up in Figure 4 in given interval durations $(\mathrm{t})$ by $15 \mathrm{~s}$ where the actual time denotes tx $i$. In the direct heating for 563 and $588{ }^{\circ} \mathrm{C}$, the initial temperature rises to 390 , and $500{ }^{\circ} \mathrm{C}$ in the duration $\pm 100 i$ then attained the balanced state in $180 i$ and $220 i$ $( \pm 1.6$ hours), respectively. On the other side, in the gradual heating, the chosen temperatures are $550^{\circ} \mathrm{C}$ and $575{ }^{\circ} \mathrm{C}$. The temperature $550^{\circ} \mathrm{C}$ rises to $+150{ }^{\circ} \mathrm{C}$ in the duration $<100 i$, fluctuated at $300{ }^{\circ} \mathrm{C}<\mathrm{T}<400$ ${ }^{\circ} \mathrm{C}$ in the $250 i<t<500 i$, and reaches the balanced heat at $563^{\circ} \mathrm{C}$ in the $630 i$. Moreover, The temperature $575^{\circ} \mathrm{C}$ rise is 163 oC from the initial temperature in the $165 i$ then fluctuates at $100^{\circ} \mathrm{C}<T<520^{\circ} \mathrm{C}$ and attains the balanced temperature at $520^{\circ} \mathrm{C}$ in the $520 i$. In this whole process needed $+2,4$ hours.

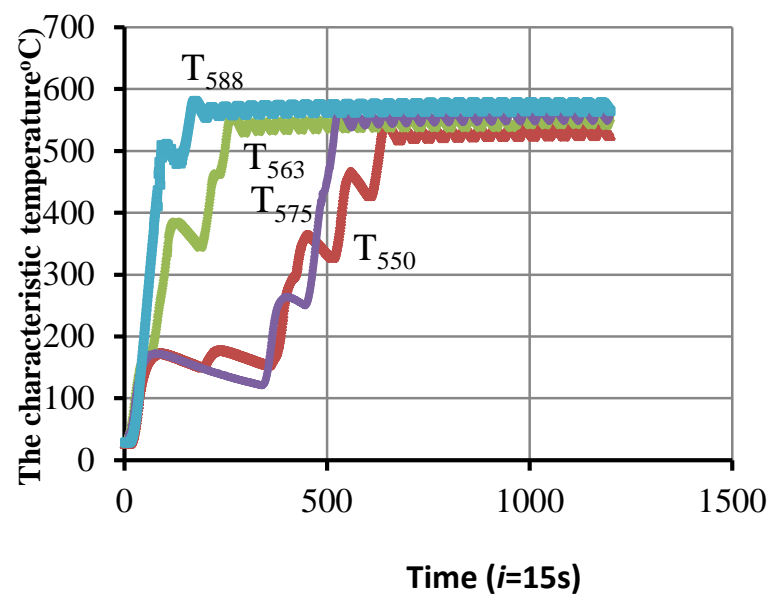

Figure 4. The characteristic temperature in the different temperatures setup for the direct and gradual heating process.

The different patterns of the rise characteristics temperature show the inconsistencies of the chamber temperature in each process for having the optimum stable temperature. The differences in the complete process, i.e., 1,6 and 2,4 hours represents time efficiency in an ashing process. It shows that the direct heating process has better performance in the time efficiency than the gradual heating process. Eventhough the direct heating process increased the time efficiency, it caused quick heating which giving effects on the ash content analysis. Oherwise, it needed longer time for the gradual heating process in the entire experiment but the lost of a specific content during the heating process can be avoided.

Meanwhile, the characteristics temperature of the chamber investigated in two stages. The first step was the initial incineration to maintain the desirable temperature setups. The second step was analization when the chamber reached a stable condition. Representation of the characteristics temperature is showed in Fig. 5. In Fig. 5, The characteristic temperature drawed based on the regression coefficient $(b)$, and the coefficient of determination $\left(\mathrm{R}^{2}\right)$ for every 15 minutes (tx60). The thermocontrol setup point is determined when $b$ and $\mathrm{R}^{2}$ are at the stable and lowest value within at least 1 hour (tx60x4) in the observation.

It set up the thermo-control temperature $550{ }^{\circ} \mathrm{C}$ and $575{ }^{\circ} \mathrm{C}$ for the gradual burning process. It can be noticed in Fig. 5 that when the thermo-control temperature is set up 550 ${ }^{\circ} \mathrm{C}$, the temperature fluctuation occurred until the stable condition achieved at $\mathrm{t}=270$ (180 minutes). When the temperature was $575{ }^{\circ} \mathrm{C}$ the stable point is obtained at $\mathrm{t}=600(150$ minutes) in which this duration is \pm 30 minutes faster than the thermo-control temperature $550{ }^{\circ} \mathrm{C}$.

In addition, In the direct burning process was chosen $563{ }^{\circ} \mathrm{C}$ and $588{ }^{\circ} \mathrm{C}$ as the thermocontrol temperature set-up. Heading to Fig. 5, when the temperature set up $636{ }^{\circ} \mathrm{C}$, it required $\mathrm{t}=360$ (90minutes) to reach the stable condition, while it spent $\mathrm{t}=240(60$ minutes) for the temperature set up $588{ }^{\circ} \mathrm{C}$.

In these senses, the direct burning process needs the shorter time to reach the stable condition comparing to the gradual process. It is due to the direct thermo-control setup in the direct burning process used a single step of the initial incineration in which the energy consumption was smaller compared to the gradual burning process. The high energy 
consumptions can cause energy inefficiency and high analysis cost. It is common that utilization of an electrical furnace spends a high cost corresponding to the consumed energy and the length of the used time. ${ }^{13}$

\section{Temperature Uniformity}

The temperature distribution in the work space is an essential way of studying the accuracy performance of the muffle furnace. The uniformity classification of the given muffle furnace refers to the uniformity classification AMS2750 in Jones and Fradette. ${ }^{14}$ Based on Table 1, the temperature uniformity among all treatments are not significantly different, $\pm 6.45{ }^{\circ} \mathrm{C}$ to \pm 6.77 ${ }^{\circ} \mathrm{C}$, and the overall uniformity is $6,61{ }^{\circ} \mathrm{C}$. It classifies the given muffle furnace into the $3^{\text {rd }}$ classes $\left( \pm 8^{\circ} \mathrm{C}\right)$.

Moreover, the average accuracy has a range from $1.11{ }^{\circ} \mathrm{C}$ to $1.23{ }^{\circ} \mathrm{C}$, which the 550 ${ }^{\circ} \mathrm{C}$ setup is notably different from the $588{ }^{\circ} \mathrm{C}$ setup, with the overall accuracy is $\pm 1.18 \%$. The temperature gradient is $26.41{ }^{\circ} \mathrm{C}-33.65$ ${ }^{\circ} \mathrm{C}$. The difference of the temperature gradients is obvious at $575{ }^{\circ} \mathrm{C}$ whose the highest gradient, $\pm 28.69{ }^{\circ} \mathrm{C}$. These represent the average fluctuation among all treatments remain unchanged in the $+20,95{ }^{\circ} \mathrm{C}$. The fluctuation is high which is caused by the used muffle furnace was one stage furnace. It means that the furnace only operates $\mathrm{ON}$ and OFF which may lead to high fluctuation for the actual temperature in the chamber.

The temperature uniformity in the work spaces showed by the temperature distribution two hours after the stable stage reached. The temperature distribution along the right side of the work space column, 1011-12, as seen in Fig. 6 was the highest comparing to the other columns. The cup 1,3, and 4 show the decrease of the temperature. Generaly speaking, the temperature in the left side (the column 1) is smaller than the temperature in the right one (the column 3 ). However, the column 2 presents the different behavior in which the cup 5 has the highest temperature. The temperature distribution shall be elaborated in the following discussion regarding the temperature homogenity.

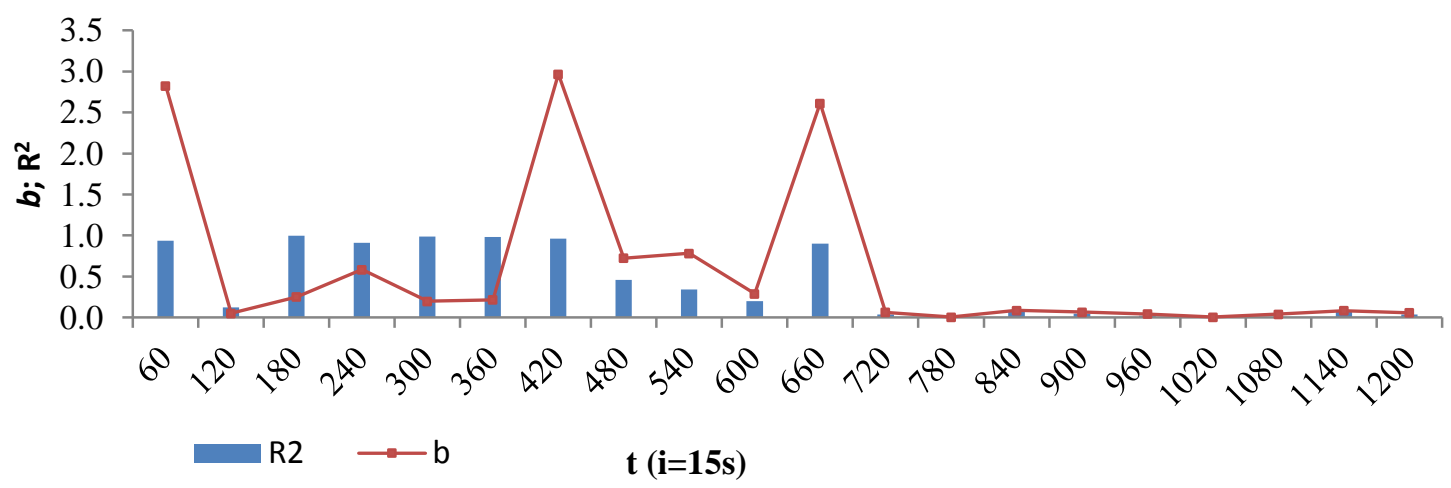

(a) $550{ }^{\circ} \mathrm{C}$

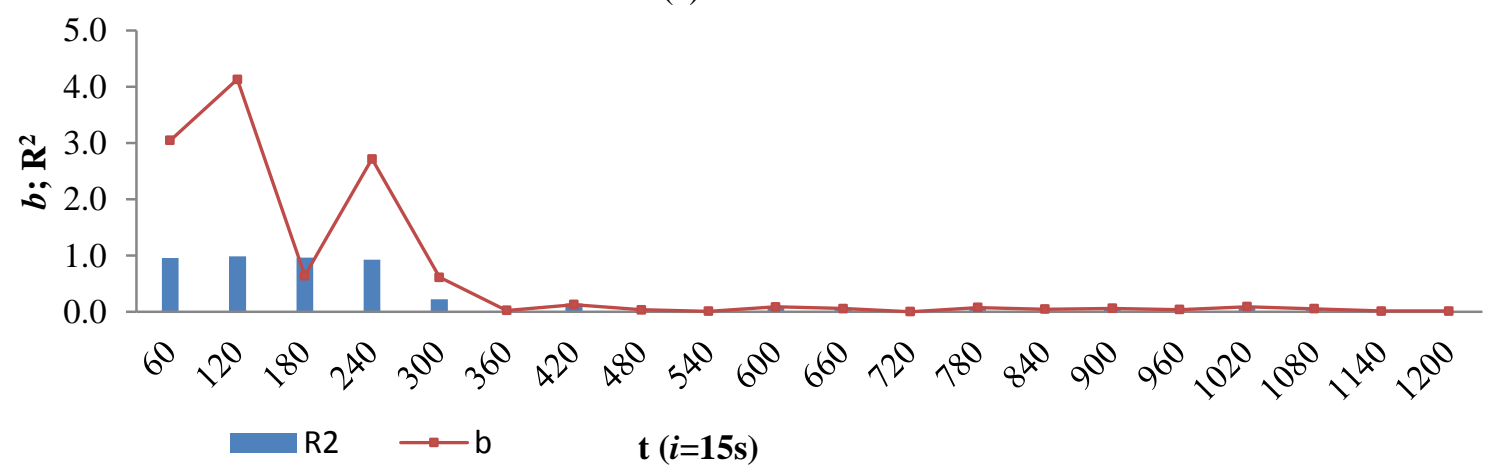

(b) $563{ }^{\circ} \mathrm{C}$ 

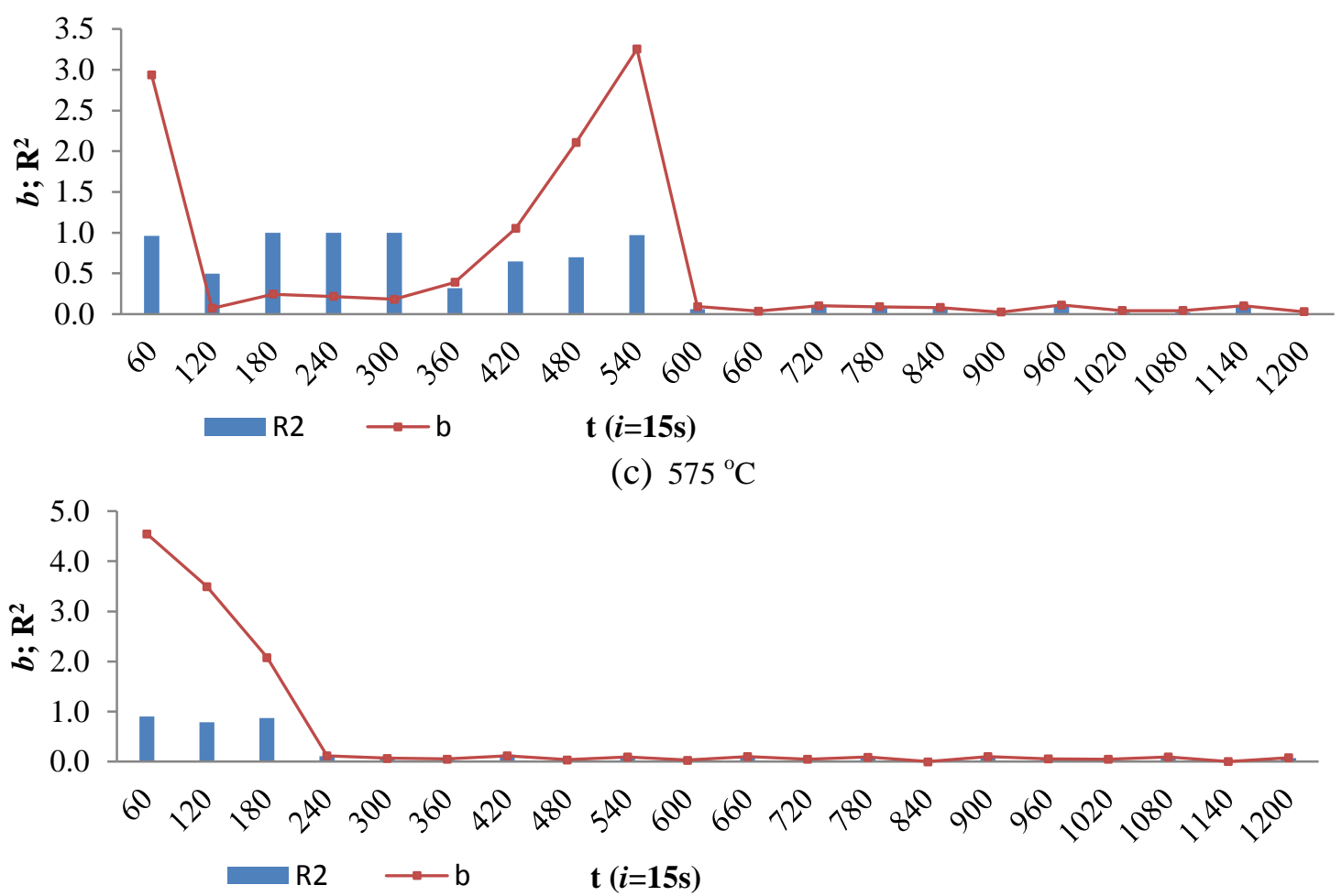

(d) $588^{\circ} \mathrm{C}$

Figure 5. The relation between the regression coefficient (b) $: \mathrm{R}^{2}$ and time in every 15 minutes

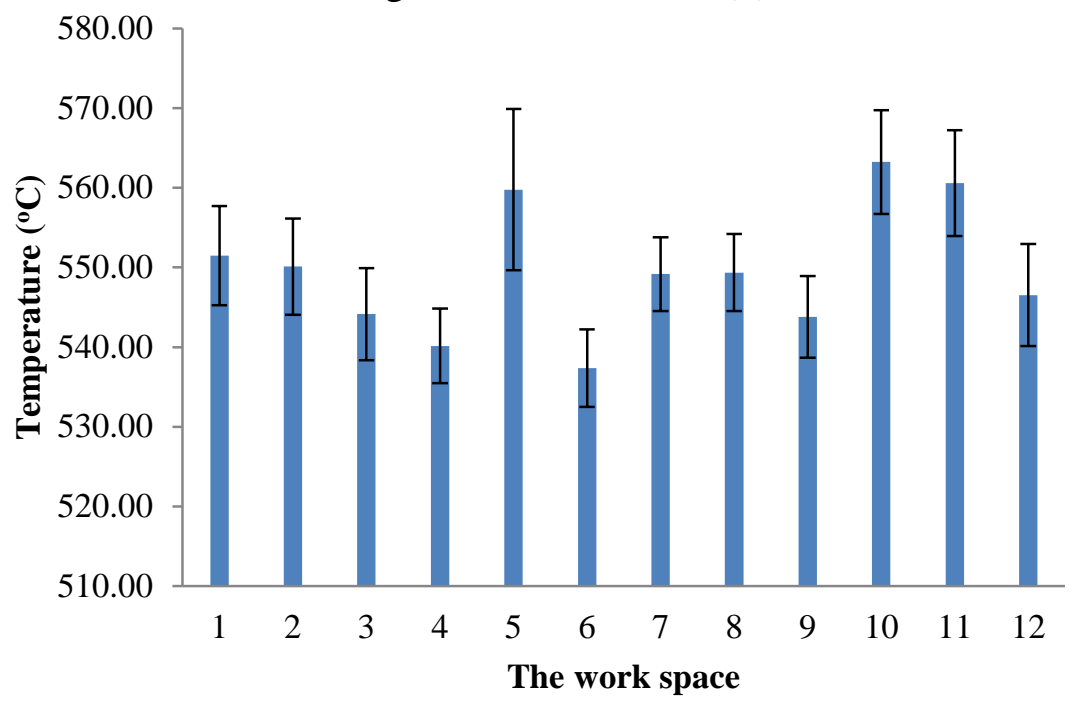

Figure 6. The temperature distribution in the work spaces

\section{Temperature Homogenity}

The points of measurents was positioned into the 12 work spaces (ceramics cups) arranged in three rows and four columns. As a result, the different positions affect on the various of heat transfer result inside the chamber. For obtaining linearity, The test of homogeneity is required to analize the actual temperature heterogenities inside the chamber in which it is represented through the coefficient of linear regression.

The temperature homogeneity measured in each work space was correlated to the temperature in every column and row of the work space. In Fig. 7, It shows that the distribution of temperature in each column and row is homogen $\left(\mathrm{F}_{\mathrm{cal}} .<\mathrm{F}_{\text {table }}\right)$ with the homogeneity level is $5 \%$. The back side of the column, numbered $1,4,7$, and 10 , has the significant high temperature in rate 
comparing to the front side which is numbered by 3, 6,9 and 12. Moreover, the temperature distribution over the row does not represent non-heterogenic $\left(\mathrm{F}_{\text {cal. }}<\mathrm{F}_{\text {table }}\right)$ with homogeneity level $5 \%$. The temperature on the left side ( cup 1,2, and 3) is smaller than the right side ( cup 10,11, and 12). The homogeneity both in the rows and the columns of the work space reflected the accuracy of the furnace.

The uniformity of temperature prior to the accuracy and performance of the furnace referred to its structural design i.e.: heater and sensor position; dimension; heat transfer method; and control system. A well developed design refers to the device ability to manage the equal distribution of heat transfer from the heater and temperature reading in the thermo-control system.

Two types of muffle furnace with a good performance operate in different way namely two stage operations and modulating furnace. The two stage furnace operates in turn $\mathrm{ON}$ and OFF but also has a low output that runs around at lower capacity. Furthermore, a modulator furnace employs a valve function that reduce the energy intake to the heater. After heated to the maximum power, then it will gradually decrease its heating power as the heat rise up. This operation may produce more efficient temperature distribution ${ }^{15}$ and performs lower fluctuation.

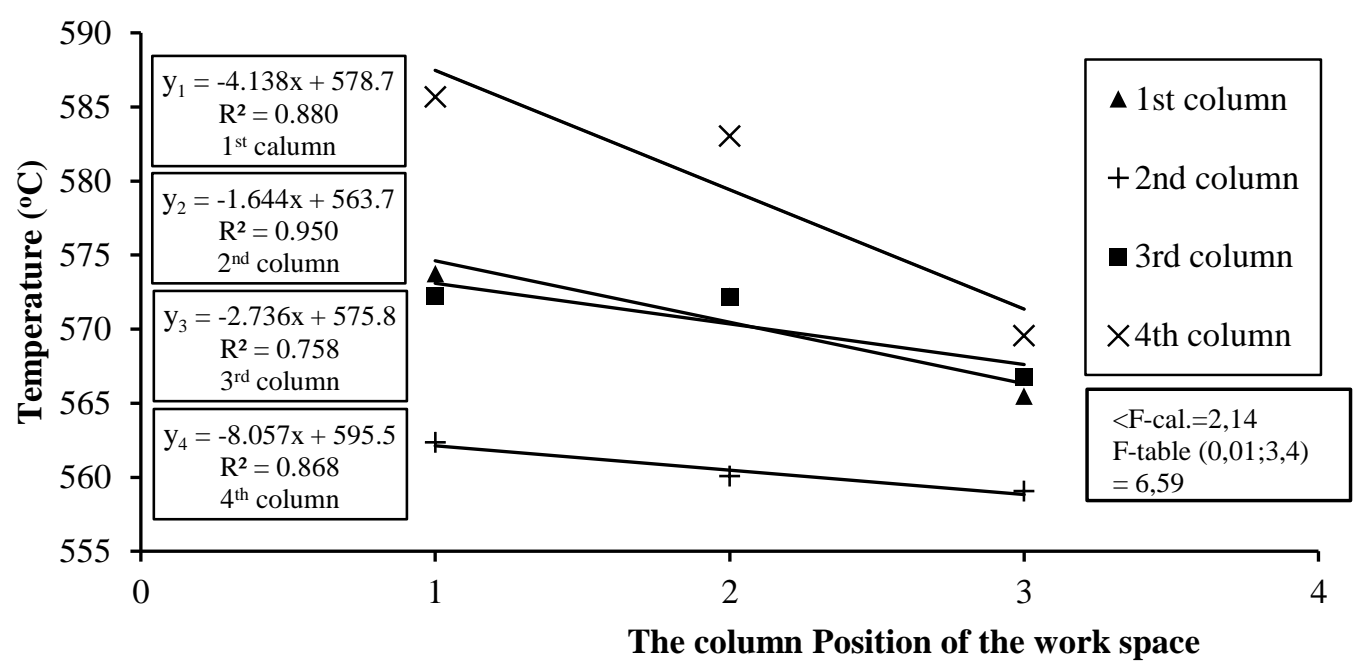

(a)

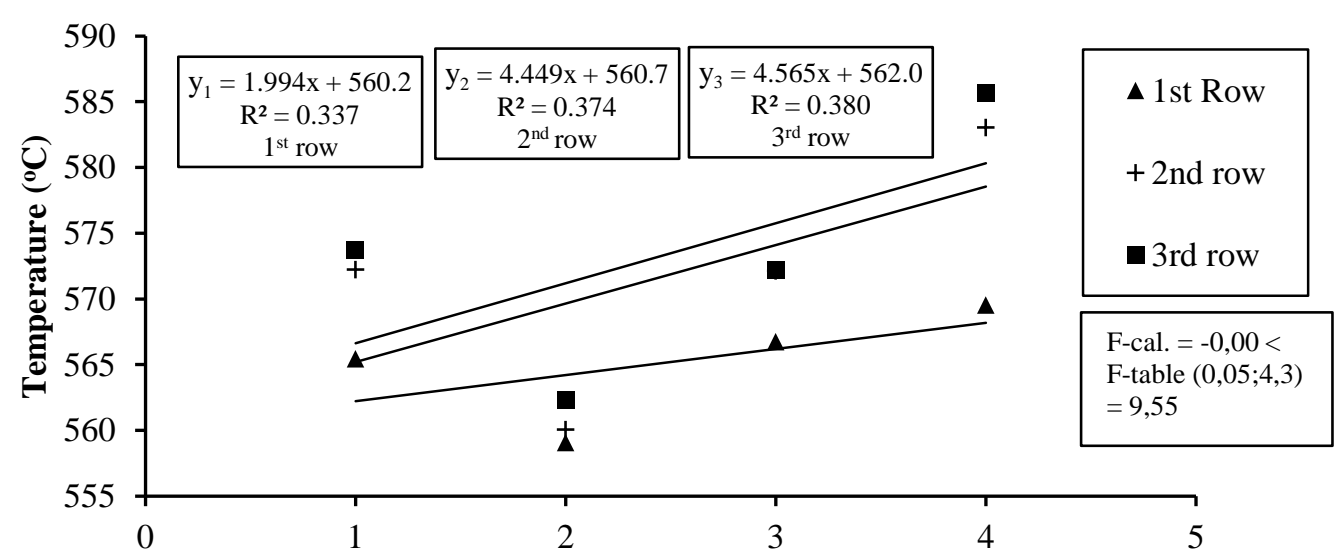

The row position of the work space

(b)

Figure 7. The temperature homogeneity (a) the column position (b) the row position. 


\section{Optimum Temperature Setup}

The optimum temperature setup as the main idea of this study was mainly achieved from the observation of 4 treatments included $550{ }^{\circ} \mathrm{C} ; 563{ }^{\circ} \mathrm{C} ; 575{ }^{\circ} \mathrm{C} ; 588{ }^{\circ} \mathrm{C}$. The desired setup as for ash content analysis to $575 \pm 25$ ${ }^{\circ} \mathrm{C}$ employed the lower bond of $550{ }^{\circ} \mathrm{C}$ and the upper bond of $600{ }^{\circ} \mathrm{C}$. Figure 4 described the characteristic of each treatment that showed the optimum setup at $588{ }^{\circ} \mathrm{C}$ for the given muffle furnace using the current method of temperature measurement. At the $550{ }^{\circ} \mathrm{C}$ setup, all points were excluded from the temperature setup range $\left(\mathrm{T}<550{ }^{\circ} \mathrm{C}\right.$ and $\mathrm{T}>600{ }^{\circ} \mathrm{C}$ ). Mean while, at $563{ }^{\circ} \mathrm{C}$ setup, there was one point which included; and for $575{ }^{\circ} \mathrm{C}$ setup there were 4 which included. Otherwise at $588{ }^{\circ} \mathrm{C}$ setup, all location were found to be included in the required actual

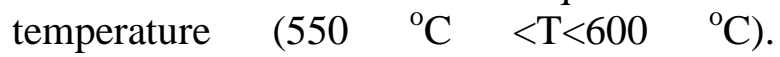

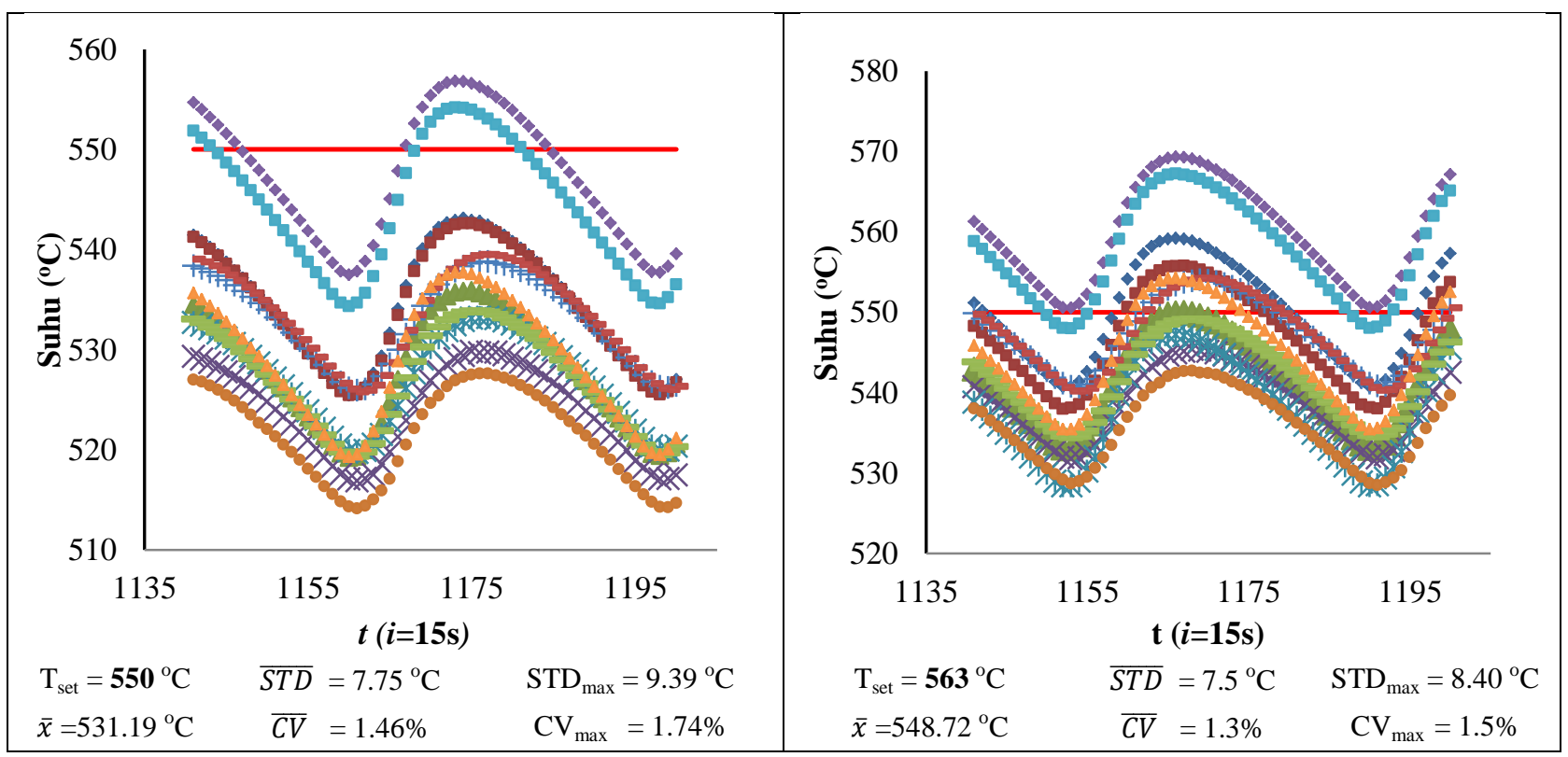

(a) $550{ }^{\circ} \mathrm{C}$

(b) $563{ }^{\circ} \mathrm{C}$

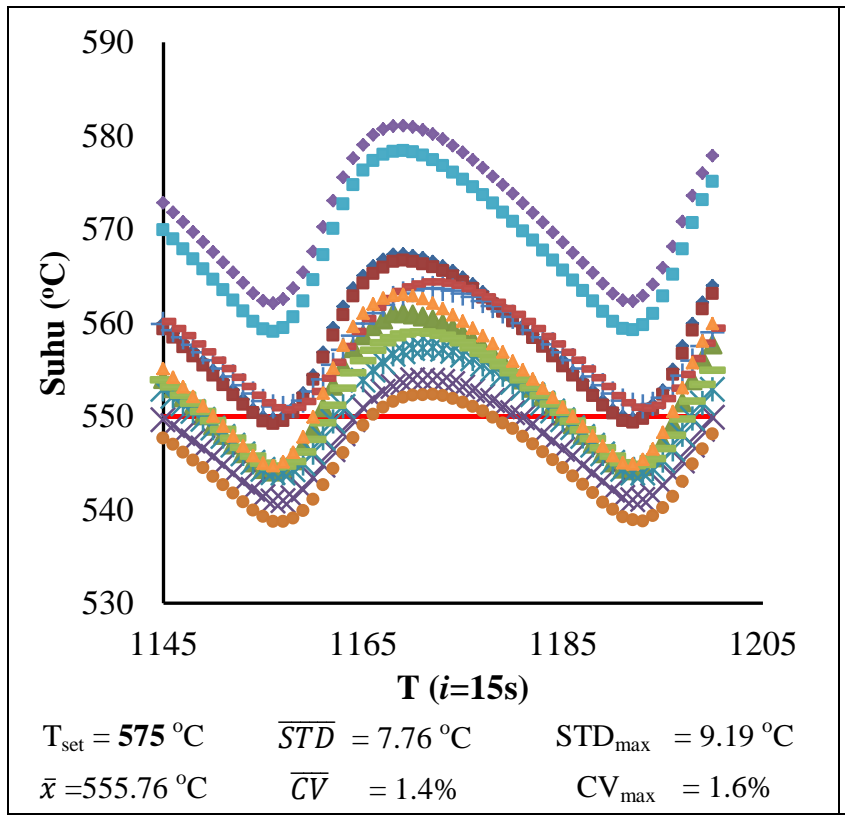

(c) $575{ }^{\circ} \mathrm{C}$

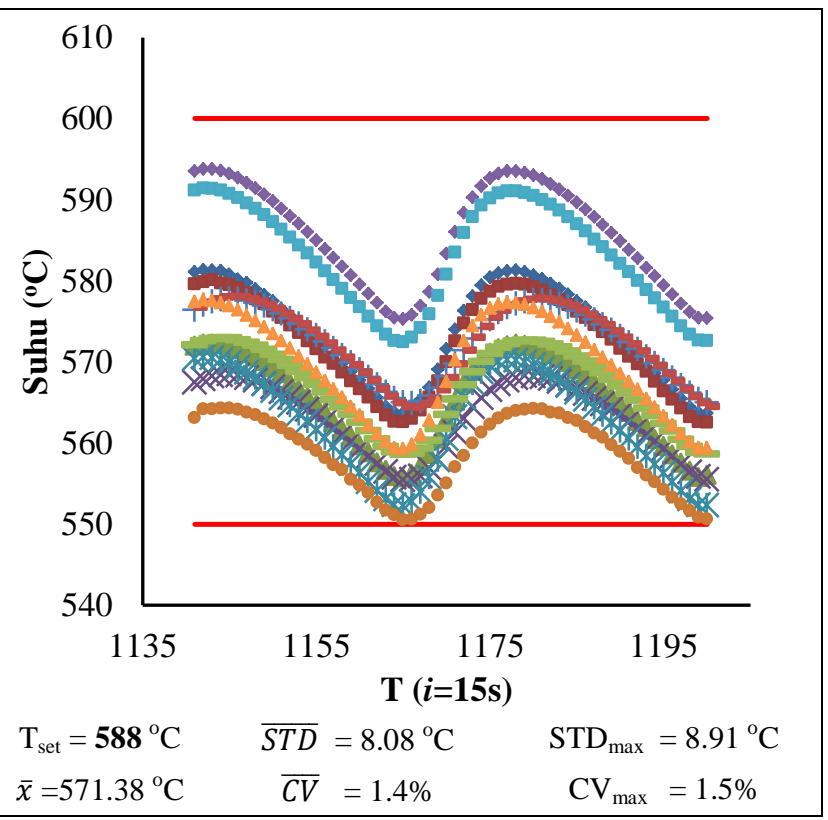

(d) $588^{\circ} \mathrm{C}$

Notes:

- Marker symbols are: 


$$
\begin{array}{llll}
* \text { Therm_1 }\left({ }^{\circ} \mathrm{C}\right) & \text { Therm_2 }\left({ }^{\circ} \mathrm{C}\right) & \Delta \text { Therm_3 }\left({ }^{\circ} \mathrm{C}\right) & \times \text { Therm_4 }\left({ }^{\circ} \mathrm{C}\right) \\
\text { * Therm_5 }\left({ }^{\circ} \mathrm{C}\right) & - \text { Therm_6 }\left({ }^{\circ} \mathrm{C}\right) & + \text { Therm_7 }\left({ }^{\circ} \mathrm{C}\right) & \text { - Therm_8 }\left({ }^{\circ} \mathrm{C}\right) \\
- \text { Therm_9 }\left({ }^{\circ} \mathrm{C}\right) & \rightarrow \text { Therm_10 }\left({ }^{\circ} \mathrm{C}\right) & \text { Therm_11 }\left({ }^{\circ} \mathrm{C}\right) & \Delta \text { Therm_12 }\left({ }^{\circ} \mathrm{C}\right)
\end{array}
$$

- $\mathrm{T}_{\text {set }}$ : Temperature set; $\bar{x}$ : Average actual temperature; $\overline{S T D}$ : Average standard deviation; $\mathrm{STD}_{\max }$ : Maximum standard deviation; $\overline{C V}$ : Average coefficient of variation; $\mathrm{CV}_{\max }$ : Maximum coefficient of variation.

Gambar 8. Temperature distribution in the latest of 12.5 minutes for 12 observation points inside the muffle furnace chamber for each temperature setup of $550{ }^{\circ} \mathrm{C} ; 563{ }^{\circ} \mathrm{C} ; 575{ }^{\circ} \mathrm{C}$; and $588{ }^{\circ} \mathrm{C}$.

The actual temperature distribution offered an empirical evidence of the muffle furnace based on the temperature setups and the accuracy of the $\mathrm{K}$ thermocouple sensor. According to Singh and Heldman ${ }^{16}$, some other factors may be considered to affect the temperature reading i.e.: type of datalogger; thermocouple wire; electrical disturbance; and type of the cold junction.

\section{Conclusion}

It can be summarized that for the indirect setup, the initial heating stage reached at $\mathrm{t}=600-720$ (150-180 minutes) followed by stability and for the direct setup, the initial heating stages required $\mathrm{t}=240-360 \quad(60-90$ minutes) and then followed by its stable condition. There was no significant different on temperature uniformity among all treatments where the overall temperature uniformity was found at $\pm 6.61{ }^{\circ} \mathrm{C}$. the furnace is then classified into the third classes $\left( \pm 8{ }^{\circ} \mathrm{C}\right)$ of uniformity. The overall accuracy was $\pm 1.18 \%$; where the $550{ }^{\circ} \mathrm{C}$ setup was different significantly from $588{ }^{\circ} \mathrm{C}$ setup. The overall temperature gradient was $\pm 28.69{ }^{\circ} \mathrm{C}$, where it was significantly different in specific among others at $575{ }^{\circ} \mathrm{C}$ of setup. Moreover, there were no significant different of the average fluctuation between all treatments which ranged at $\pm 20.95{ }^{\circ} \mathrm{C}$. The optimum setup was found at $588{ }^{\circ} \mathrm{C}$ toward the desired temperature setup for common ash analysis in biomass.

\section{Acknoledgement}

Author expresses his sincere gratitude the Laboratory of Thermal Properties and the Laboratory of Food Chemistry of Indonesian Legume and Tuber Crops Research Institute (ILETRI) for the support, and assistance.

\section{References}

1. Zhang, H.; Pu, W. X.; Ha, S.; Li, Y.; and Sun, M., 2009. The influence of included minerals on the intrinsic reactivity of chars prepared at $900{ }^{\circ} \mathrm{C}$ in a drop tube furnace and a muffle furnace. Fuel, 2009; (88): 2303-2310.

2. Gao, Q.; Liu, H.; Cheng, C.; Li, K.; Zhang, J.; Zhang, C.; and Li, Y., 2013. Preparation and characterization of acticvated carbon from wool waste and the comparison of muffle furnace and microwave heating methods. Powder Technology, 2013; (249): 234-240.

3. Harris, G.K.; and Marshall, M.R. Ash Analysis in Nielsen, S.S., Food Analysis, Food Science Text Series (p:287-297). Springer Science + Business Media. 2017.

4. AOAC International. Official methods of analysis, 20th edn. (On-line). AOAC International, Rockville, MD. 2016.

5. Sluiter A.; Hames, B.; Ruiz, R.; Scarlata, C.; Sluiter, J. and Templeton, D. Determination of ash in Biomass. Laboratory Analytical Procedure (LAP). National Renewable Energy laboratory. 2008.

6. Jones, W. R., and Fradette, R.J. Optimizing Procedures For Temperature Uniformity Surveying of Vacuum Furnaces, Vacuum furnace reference series No. 2. Solar Atmospheres, Inc \& Solar Manufacturing, Inc. 2011.

7. Abdelaziz, Y.A. Guidelines for assessment of temperature uniformity and investigation of the measurements uncertainty within laboratory oven. XVII IMEKO World Congress, Metrology in the $3^{\text {rd }}$ Millenium. Dubrovnik, Croatia. 2003. 
8. Marshall, M.R. Ash Analysis in Nielsen, S.S., Food Analysis, Food Science Text Series (p:105-115). Springer Science + Business Media. 2010.

9. (WHO) World Health Organization. Calibration of temperature control and monitoring devices. Technical supplement to WHO technical report series, No. 961. 2014.

10. Anonymous. Temperature uniformity and system accuracy. 2017. Available from: www.nabertherm.com.

11. Omni Instruments. DT80, DT81, DT 85 Users Manual. Omni Instruments. Australia/Asia Pasific. 2007.

12. (ILETRI) Indonesian Legume and Tuber crops Reseacrh Institute. Calibration certificate of a Furnace (Nabertherm/ D2804). Institute of Device Quality Certification Testing, Ministry of Trade and Industry. Surabaya. 2016.

13. (ILETRI) Indonesian Legume and Tuber crops Reseacrh Institute. Nabertherm Muffle Furnace Work Instructions. Laboratory of Food Chemistry, Indonesian Legume and Tuber Crops Research Institute (ILETRI). Malang. 2009.

14. Abadi, F.R. and Tastra, I.K.. Data Logger's Performance Of "datataker DT80" Using Two Kinds of Type K Thermocouple in Thermal Characteristic Measurement of Agricultural Material. National Seminar on Legume and Tuber Crops, Indonesian Legume and Tuber Crops Research Institute (ILETRI). 2017. in press.

15. Brand, L. and Rose, W. Measure Guideline: High Efficiency Natural Gas Furnaces. Energy Efficiency and renewable Energy. United States Department of Energy. 2012.

16. Singh, R.P. and Heldman. Food and Science Technology (5 ${ }^{\text {th }}$ Edition). Academic Press. 2014. 